\title{
DEEP DISAGREEMENTS ON VALUES, JUSTICE, AND MORAL ISSUES: TOWARDS AN ETHICS OF DISAGREEMENT
}

\author{
Manuel Knoll \\ Turkish-German University, Istanbul
}

\begin{abstract}
Scholars have long recognized the existence of myriad widespread deep disagreements on values, justice, morality, and ethics. In order to come to terms with such deep disagreements, resistant to rational solution, this article asserts the need for developing an ethics of disagreement. The reality that theoretical disagreements often turn into practical conflicts is a major justification for why such an ethics is necessary. This paper outlines an ethics of deep disagreement that is primarily conceived of as a form of virtue ethics. Such an ethics asks opposing parties in moral and intellectual conflicts to acknowledge that (a) deep disagreements exist, (b) opposing positions should be recognized as worthy of respect, and that (c) one should seek dialogue and mutual understanding. This ethical approach conceives of toleration as a moral and political virtue and presents an argument for toleration based on deep disagreements.
\end{abstract}

Keywords. value conflicts, justice conflicts, moral disagreements, virtue ethics, conflict research, toleration, respect, public reason

DOI: https//doi.org/10.3176/tr.2020.3.04

\section{The contemporary awareness of moral disagreements and value conflicts}

The modern world is not only a world characterized by moral disagreements and value conflicts but a world that is well aware of such disagreements and conflicts. People disagree on essentials such as religion, values, politics, and the good life and on specific moral issues such as capital punishment, gay marriage, and preferential hiring. For the later Rawls, a "modern democratic society is characterized not simply by a pluralism of comprehensive religious, philosophical, and moral doctrines but by a pluralism of incompatible yet reasonable comprehensive doctrines" (Rawls 2005: 
XVI). Nietzsche even claims that serious value conflicts are a feature of most of human history. According to his Genealogy of Morality, the "two opposing values 'good and bad,' 'good and evil' have fought a terrible battle for thousands of years on earth" (Nietzsche 1997, I 16: 31). Following Nietzsche, Max Weber holds that modernity is characterized by both an irresolvable pluralism and struggle of values. For Weber, scientific reason is unable to determine which of two or more conflicting goals or values is more desirable or worth choosing (Weber 1949). Similarly, Isaiah Berlin claims that there is a pluralism of incompatible values and that the clash of these values is rationally irresolvable (Berlin 1997: 6-16, Berlin 2013: 94-99). In his Theory of Justice, Rawls (1971) tries to cope with disagreements over the good by arguing for a rational agreement on a liberal conception of justice and a just political framework that allows opposing conceptions of a good life to coexist. In Political Liberalism, Rawls claims that in a pluralist society, in which different persons accept incompatible yet reasonable comprehensive doctrines, an "overlapping consensus" on a political conception of justice can be reached (Rawls 2005, IV §§ 1-8: 133172, cf. Mason 1993: 9-12). However, recent research has convincingly argued that a rational agreement or an "overlapping consensus" on justice is not a realistic goal; thus we must come to terms with deep disagreements on justice and the law (Besson 2005, Hampshire 1999, Herwig 1984, Knoll 2019a, MacIntyre 1988: 1-7, Waldron 1999, Warnke 1993).

This article starts out with several arguments for the thesis of deep disagreements, according to which widespread and deep disagreements on values, justice, and moral issues exist that are resistant to rational solution (section 2). Deep disagreements are disagreements in good faith that cannot be resolved through the use of reasons and arguments (cf. Fogelin 2005: 8, 11). According to Robert J. Fogelin, the cause why deep disagreements cannot be resolved through the use of reasons and arguments is a clash of "underlying principles" or "framework propositions" (2005: 8-9, cf. section 2). This article does not adopt, reject or extensively discuss Fogelin's foundationalist approach. The arguments and positions introduced in sections 2 and 3 suggest that there are several different reasons why disagreements in good faith cannot be rationally resolved (for a distinction between shallow and deep epistemic disagreements and a sophisticated analysis of the latter, see Lynch 2010).

In a second step this paper asks about the attitudes, behaviors, and actions we should take towards those with whom we disagree, but have to live with. As private persons we disagree with our partners, relatives, friends, colleagues and neighbors on a wide range of topics, as citizens we conflict with the moral and political views of the political parties our fellow citizens vote for, and as researchers, experts and philosophers we disagree with our colleagues about a variety of scientific and philosophical issues.

This article claims that in order to come to terms with deep disagreements we should develop an ethics of disagreement. A major justification for the necessity of such an ethics is that theoretical disagreements often turn into practical conflicts (section 3). This paper outlines an ethics of deep disagreement that is primarily conceived of as a form of virtue ethics. Most fundamentally, such an ethics asks 
opposing parties in moral and intellectual conflicts to recognize and admit that deep disagreements exist. This means that the conflicting parties should not oversimplify the matter by degrading the opponent as ignorant, irrational, unintelligent, insincere, malicious, and the like without evidence or good reasons. This means as well that one should recognize that an opposing position is worthy of respect even if one thinks that it is wrong. Respect of this kind should be a main motivation for seeking dialogue and for hearing the opponent's reasons and arguments for her position. In the language of virtue ethics the mentioned attitudes could be designated as the virtues of acknowledging deep disagreements and of recognizing opposing positions as worthy of respect and as the virtue of seeking dialogue and mutual understanding (sections 3 and 4). Both virtues should lead to a better comprehension of opposing positions and might in certain cases even show the way to a resolution of moral or intellectual conflicts.

Deep disagreements on values, justice, and moral issues occur in particular in the political arena. Citizens and political parties disagree on appropriate or just laws concerning abortion, taxation, and human cloning. An ethics of deep disagreements in politics stresses in particular the virtue of seeking dialogue and mutual understanding and puts emphasis on free speech, public debates, and public reason. In general, it favors deliberative democracy in which moral arguments about public policies are exchanged in public forums. An ethics of disagreement does not hope for consensus. Rather, it stresses bargaining and compromise and claims that procedures such as majority rule are necessary to resolve moral conflicts in a fair and peaceful way (section 4).

An ethics of disagreement needs to include reflections on toleration as a moral and political virtue (section 5). In the past, the value of intercultural tolerance has been emphasized in particular by anthropologists in the context of moral diversity and cultural ethical relativism. ${ }^{1}$ Because widespread moral disagreements undermine moral objectivism and ethical realism, it has been argued that we should tolerate those with whom we disagree (cf. Gowans 2000: 6-9, 33-35). Section 5 presents an argument for toleration based on deep disagreements claiming that acknowledging deep disagreements on values, justice, and moral issues and recognizing opposing positions as worthy of respect has important consequences for the debate on toleration.

The ethics of disagreement rests on a meta-ethical and epistemological position that could be called 'moderate relativism' or 'moderate skepticism'. This position

Cf. section 2. Cultural ethical relativism starts out from the (anthropological) diversity thesis, according to which what is morally right in one culture may be wrong in another. This means that there are "no universal standards held by all cultures". In a second step, cultural ethical relativism defends the "dependency thesis", which claims that all "moral principles derive their validity from cultural acceptance" (Pojman and Fieser 2012: 19, cf. 14-21). As there are no universal and objective moral principles valid for all cultures, anthropologists argue that we should avoid ethnocentrism and tolerate the moral views of other cultures. 
rejects ethical realism and cognitivism'; it equally rejects both an 'absolute skepticism' ("no truths can be discerned") and an 'absolute relativism' ("everything is true or morally valid only for an individual or group"; "de gustibus disputandum non est"). The ethics of disagreement defends attitudes and virtues that are inextricably linked or even identical with certain values such as respect, dialogue, toleration, and peaceful coexistence. Such an ethics does not claim that these values are true, objective, and universally valid or that they can be demonstrated or rationally grounded in an ultimate way. Nevertheless, it contends that they are more beneficial or can be defended with better reasons and arguments than other values such as racial superiority, intolerance, conquest, and war. ${ }^{3}$ In line with this, the ethics of disagreement asserts that not all behaviors, beliefs or values can be tolerated (section 5). Similarly, not all views and beliefs about the world are equally rational and defensible. Some are logically consistent and in line with our observations and experiences, others are not. For a comprehensive defense of 'moderate relativism' and 'moderate skepticism', and a discussion of the relation between different forms of relativism and skepticism, and of how these exactly relate to the values of an ethics of disagreement, a further article would be needed.

\section{Arguments for the thesis of deep disagreements}

Moral disagreements are frequently discussed in connection with the claims that moral judgments are objective and express universally valid truths (for definitions of moral objectivity, see Gowans 2000: 3 and Pojman and Fieser 2012: 31-32). In the contemporary debate, it is common to refer to basic human rights for moral judgments that are objective and have universal authority (cf. Gowans 2000: 4-6). In the debate, several different arguments against moral objectivism have been advanced (cf. Gowans 2000: 13-15). An important one is the argument from moral disagreement. If morality were objective, "reasonable and well-informed persons would tend to agree about their moral beliefs" (Gowans 2000: 3-4). It is reasonable to expect agreement in such cases because we can observe considerable agreement on the knowledge of the natural sciences. This knowledge is usually held to be

2 In contemporary meta-ethics, cognitivism is the position that moral knowledge exists and that moral judgments express beliefs that can be true or false (Miller 2013: 3). This position is often linked to another one called 'moral realism' or 'ethical realism' which claims that moral facts or objective moral values exist in mind-independent ways (Miller 2013: 5, Rüther 2015: 93-123). Folke Tersman equates the 'realist' view on ethics with the 'objectivist' view. Both views claim "that moral issues are issues over matters of fact, issues that allow for objectively and uniquely true answers" (Tersman 2006: xi-xii).

3 A similar view is defended by the sophist Protagoras who holds that in moral matters there are no universal truths. However, for good reasons he argues that some moral beliefs or views about the good and just are more beneficial or useful than others (Plato, Theaetetus 166d-167d, 172a-b, 177d-e; for Protagoras's position, see Giorgini 2019: 107-114). In the conclusion, this article argues that an ethics of disagreement is open to amendment by elements from a consequentialist or utilitarian ethics that aims at an increase in pleasure and a reduction of pain and suffering (or happiness or human welfare or the satisfaction of informed preferences). 
objective and its objectivity is commonly taken to be the reason for the agreement among natural scientists. Nevertheless, also natural scientists often disagree with each other, and the 'objective' results of the natural sciences partially depend on 'subjective' methods and perspectives.

In the area of morality we cannot detect any agreement on moral beliefs. Rather, "there are widespread and deep moral disagreements that appear persistently resistant to rational solution" (Gowans 2000: 2, cf. 18-22). In modern societies people disagree on specific moral issues such as affirmative action, euthanasia, and surrogate motherhood. Considering the depth and insolubility of moral disagreements, it is very improbable that morality is objective (for a detailed account of the disagreement argument against moral objectivity, see Gowans 2000: 15-18). ${ }^{4}$

The argument against moral objectivism from moral disagreement is closely related to the similar argument from relativity. This argument "is actually an argument from disagreement" (Machuca 2013b: 5). Based on history, anthropology, ethnology, and sociology, we know today that there is a wide range of diversity in moral beliefs. This diversity, and we could add the existence of all kinds of moral disagreements and disagreements on values, is the premise of the argument from relativity. This argument claims that moral diversity suggests "that there are no absolute universal moral standards binding on all men at all times" and that the validity of moral beliefs and principles depends on their cultural or individual acceptance (Ladd 1985: 1, 3). This argument against moral objectivism is also an argument against ethical realism and cognitivism. According to John L. Mackie, the argument "has some force simply because the actual variations in the moral codes are more readily explained by the hypothesis that they reflect ways of life than by the hypothesis that they express perceptions, most of them seriously inadequate and badly distorted, of objective values" (Mackie 1977: 37). If universal moral truths existed, contradicting norms and moral standards could not be true. The huge amount of existing moral diversity and disagreement suggests that no moral view can be understood as the apprehension of the one objective moral truth (cf. Birnbacher 2003: 391-92, Waldron 1999: 177).

Christopher W. Gowans calls the thesis that "there are widespread and deep moral disagreements that appear persistently resistant to rational solution" the Disagreement Thesis (Gowans 2000: 2). However, it is more appropriate to call it the thesis of deep disagreements. In 1985, Fogelin published a paper titled "The logic of deep disagreements", which is included in Gowans's bibliography. Fogelin defines "deep disagreements" as disagreements that cannot be resolved through the use of reasons and arguments (cf. Fogelin 2005: 8, 11). Fogelin's article

4 Folke Tersman explains that there are many versions of "the argument from moral disagreement" that "take quite different routes to their antirealist conclusions". The first one "claims that the best explanation of the existing moral diversity entails that there are no objective moral truths. The alleged reason is that many moral disagreements are difficult if not impossible to resolve through rational means" (Tersman 2006: xiii). Tersman's book, which concludes that "considerations that have to do with moral disagreement do indeed refute moral realism", also focuses on an explanation of the contrast between ethics and the natural sciences (Tersman 2006: xii). For several publications on the different versions of the argument from moral disagreement "and the question of whether it succeeds in undermining moral realism", see Machuca (2013b: 19, fn. 24). 
sparked controversies on deep and peer disagreements (for a summary of the debates see Siegel 2013 and for the literature on the epistemology of disagreement Machuca $2013 \mathrm{~b}$ and Siegel 2013). One of Fogelin's examples for deep disagreements is the abortion debate: "Parties on opposite sides of the debate can agree on a wide range of biological facts" and also "on the sanctity of human life" (Fogelin 2005: 8). However, "the central issue of the abortion debate is the moral status of the fetus", and in regard to this issue the one party believes that, at conception or shortly afterwards, "an immortal soul enters into the fertilized egg" and the other party does not. There is no way of solving such a disagreement through the use of reasons and arguments because of the irreconcilable belief systems that the disagreement is based on (Fogelin 2005: 8-9). These belief systems are the "underlying principles" or "framework propositions" of the disagreement. Deep disagreements are generated by a clash "of framework propositions" or "underlying principles", which are not isolated but a part of "a whole system of mutually supporting propositions" that constitute a "form of life" on each side of the disagreement (Fogelin 2005: 8-9). Fogelin's "Wittgensteinian view" of the "limits of reason" has been criticized by several authors (cf. Siegel 2013: 16-21). ${ }^{5}$ A central argument in this criticism rejects "the Wittgensteinian starting point that there is no way to evaluate" the "underlying principles" and "framework propositions" of a disagreement that constitute forms of life (Siegel 2013: 20).

Deep disagreements are disputes in good faith that are rationally irresolvable. Although Max Weber and Isaiah Berlin did not use the term 'deep disagreements', both scholars claimed decades before Fogelin that there is no possibility to rationally arbitrate between values or to rationally resolve value conflicts. Berlin's views on value pluralism and collisions of objective values appeal to thinkers such as Machiavelli, Vico, Herder, and the Russian radical Alexander Herzen (Berlin 1997: 6-14). For Berlin, "values can clash" or "be incompatible between cultures, or groups in the same culture, or between you and me"; also values "may easily clash within the breast of a single individual" (Berlin 1997: 10). Berlin illustrates value conflicts with someone who believes in always telling the truth and someone who believes that this "can sometimes be too painful and too destructive" (Berlin 1997: 10; for the clash of a deontological and a consequentialist approach to ethics see the last paragraph of this section). He further mentions the collision of liberty and equality and therefore of two major human values and goals. When different individuals exercise their liberty, it usually leads to inequality among them. The accomplishment of equality, by contrast, frequently demands the restraint of liberty; e.g. liberty needs "to be curtailed in order to make room for social welfare" (Berlin 1997: 10-11). Value conflicts are an essential feature of the human condition. In such conflicts "we are doomed to choose, and every choice may entail an irreparable loss" (Berlin 1997: 11). The "normal human situation" is that "ends equally ultimate, equally sacred" and "entire systems of value" do "come into collision without possibility of rational

\footnotetext{
5 According to Richard Feldman, disagreements can be rationally resolved "not only by one participant rationally coming around to the other's point of view, but also by both of them rationally suspending judgment about the disputed proposition" (Feldman 2005: 13). For the skeptical implications of disagreement see the articles and the introduction in Machuca (2013a).
} 
arbitration" (Berlin 2013: 94, cf. 94-99). On the basis of his views on value pluralism and collisions of values, Berlin rejects the utopian political notion of a perfect state as an unrealistic ideal and dangerous political goal; "the search for perfection does seem to me a recipe for bloodshed" (Berlin 1997: 12-13, 15). Values are human ends that differ in "some profound, irreconcilable way" and are "not combinable in any final synthesis" (Berlin 1997: 8).

Influenced by Nietzsche's thoughts on the struggle between opposing values, Max Weber developed his own theory of value conflict (for this influence see Knoll 2019b: 117-123). Weber claims that a constant struggle of opposing values and ideals is a characteristic feature of modernity (Weber 1949: 17-18). The political struggle between politicians and parties is part of this bigger and more fundamental fight. Weber's theory of value conflict is linked to his philosophy of science and in particular to his methodological thoughts on "ethical neutrality" (Wertfreiheit) of the social sciences. This well-known postulate means primarily that social scientists are unable to scientifically demonstrate which practical phenomena are "approvable" (billigenswert) and which ones are "objectionable" (verwerflich) (Weber 1949: 1). In short, "value-judgments" (Wertungen) cannot be assessed scientifically as desirable or reprehensible. Weber illustrates this with the example that it is impossible to scientifically assess and compare the value of French and German culture (Weber 1946: 148). For many centuries, as previously in Plato's philosophy, in the Christian world view different value spheres were successfully combined into a coherent unity. After the decline of Christianity in the modern world, however, this unity of the holy, the beautiful, the good, and the true broke apart. As a consequence, the distinctions between the different value spheres and their antagonisms become again visible. There exists no given or predefined "hierarchical ordering of values", but only a radical pluralism and conflict of ideals and values (Weber 1946: 147-8, Weber 1949: 1).

Weber's postulate of the "ethical neutrality" (Wertfreiheit) of the social sciences demands a clear distinction between the spheres of 'is' and 'ought', or facts and values. This demand entails that social scientists should not commit the fallacy of deriving 'ought' from 'is'. Weber asks for a strict separation of "purely logically deducible and empirical factual assertions on the one hand, and practical, ethical or philosophical value-judgments on the other" (Weber 1949: 1; for Weber's methodology and philosophy of science, see Bruun 2007). Social scientists should focus on the sphere of empirically accessible facts and their relations. Despite the limits of the social sciences and reason, sociology is able to study normative phenomena such as values and ideals empirically. In addition to the restrictions of the social sciences and reason, Weber also talks about the "the "limits' of ethics" (Weber 1949: 15). Both the social sciences and ethics suffer from argumentative limits concerning a rational or scientific grounding of values. Both are unable to scientifically answer the questions of how to act and how to live. Weber addresses these limits in a crucial statement that also refers to his "decisionism",

Even such simple questions as the extent to which an end should sanction unavoidable means, or the extent to which undesired repercussions [Nebenerfolge] should be taken into consideration, or how conflicts 
between several concretely conflicting ends are to be arbitrated [schlichten], are entirely matters of choice or compromise. There is no (rational or empirical) scientific procedure of any kind whatsoever which can provide us with a decision here (Weber 1949: 18-19).

Weber's point about the argumentative limits of ethics and the social sciences is not that the different parties in moral disagreements and value conflicts are unable to defend their views with reasons and arguments. Rather, he claims that such disagreements and conflicts cannot be definitely and conclusively argued out (Weber talks about the "Unaustragbarkeit" of such conflicts, e.g. Weber 1946: 152, Weber 1949: 11, 16). For Weber, an ultimate rational grounding of values, norm or ideals is impossible (cf. Knoll 2019b).

The central claim of the passage quoted above is that there "is no (rational or empirical) scientific procedure of any kind whatsoever" that could arbitrate between values or resolve moral disagreements and value conflicts. Weber does not indicate whether he criticizes specific rational or empirical procedures that have been proposed to solve conflicts between values, norms, and ideals. It seems quite clear that it is impossible to solve a conflict between antagonistic values applying an empirical scientific procedure. However, in contemporary political philosophy Rawls focused on rational procedures to resolve conflicts between competing conceptions of justice. In his Theory of Justice, he proposes a "contractarian method", which he uses to choose principles of justice from a list of conceptions in a fair "initial situation", integrating elements of "the theory of rational choice" (Rawls 1971, §§ 3, 21: 12, 16-17, 123-124). However, Rawls later stated that it was a "very misleading" error "to describe a theory of justice as part of the theory of rational choice" (Rawls 1985: 237, fn. 20).

In his later works, Rawls focuses more on a coherentist approach to political justice, which he already proposed in $A$ Theory of Justice. This approach attempts to produce coherence among principles of justice and "considered convictions of justice" aiming at a "reflective equilibrium" (Rawls 1971, §§ 3-4: 16-17, 19-20). Rawls claims that a democratic political culture contains "considered judgments" about justice such as "religious intolerance and racial discrimination are unjust" (Rawls 1971, §§ 4, 9: 19, 46-53, cf. Rawls 1985: 228). According to Rawls's coherentist approach, it is possible to extract both such "settled convictions" and "recognized basic ideas and principles" about justice from a "public political culture" and to seek to combine them "into a coherent conception of justice" (Rawls 1985: 228, Rawls 2005: 8). The crucial problem of this approach is, however, that the citizens of democratic political cultures display a plurality of antagonistic "considered judgments" about justice. There are liberals and libertarians, conservatives and socialists, and such like who disagree on conceptions of justice. Conflicts among values, norms, ideals, and "considered judgments" are part of one and the same political culture. Therefore, it is impossible to derive one "coherent conception of justice" from it.

In mainstream sciences, practitioners disagree with each other about, say, aspects of climate change, but there is some agreement on the methods and procedures for settling or resolving such disagreements. However, "nothing remotely comparable" 
exists when it comes to moral and ethical disagreements (Waldron 1999: 178). Nevertheless, in ethics it is possible to imagine rational procedures to solve a conflict between values, norms, and ideals. However, such procedures do not reach their goal. Take the conflict or disagreement between an ethical realist and cognitivist such as Plato and an anti-realist and moral skeptic. Plato claims both that an objective moral reality, primarily the form of the good, exists and that philosophers are able to acquire truth about it. If a philosopher who defended Plato's view, or a position similar to it, were able to both cogently demonstrate that such an objective moral reality exists and to successfully communicate her knowledge about it, she could refute the anti-realist and moral skeptic. In this case, such a philosopher could solve moral disagreements and value conflicts by pointing to the moral truths and use them as standards to assess antagonistic views and values. However, until today no undeniable moral truths have been tracked down. The ethical realist, who claims that moral facts or objective moral values exist, has the burden of proof. Supporters of this position should be able to show the anti-realist and moral skeptic how such facts and values can be detected and accessed. Moreover, they should be able to come up with a convincing answer to the well-known argument from queerness: If objective values existed, they would not only "be entities or qualities or relations of a very strange sort", but it would also be very difficult to explain how we could access them (Mackie 1977: 38). To the present day, moral realists have remained unable to convince anti-realists of their views and theories. This is another argument for the claim that neither an objective morality nor moral facts and truths exist in mindindependent ways. It gives additional support to the thesis of deep disagreements, according to which there are widespread and deep disagreements on values, justice, and moral issues that are resistant to rational solution.

The thesis that deep disagreements in good faith exist that cannot be resolved through the use of reasons and arguments is also strongly supported by philosophical disagreements on social and political justice. With the different versions of his theory of justice, Rawls mainly tries to come to terms with the opposing conceptions of the good and the different comprehensive religious, philosophical, and moral doctrines that characterize a modern pluralist society. However, his move to achieve this by striving for a rational agreement or consensus on a political conception of justice and a just social framework that allows these conceptions and doctrines to coexist does not work. As early as 1918, Max Weber argued in a compelling passage about "the 'limits' of ethics" that it is a distinctive feature of modernity that there are not only irreconcilable conceptions of the good but of the just,

The implications of the postulate of 'justice' cannot be decided unambiguously by any ethic. Whether one, for example - as would correspond most closely with the views expressed by Schmoller - owes much to those who achieve much or whether one should demand much from those who accomplish much; whether one should, e. g., in the name of justice $[\ldots]$ accord great opportunities to those with eminent talents or whether on the contrary (like Babeuf) one should attempt to equalize the injustice of the unequal distribution of mental capacities through the 
rigorous provision that talented persons, whose talent gives them prestige, must not utilize their better opportunities for their own benefit - these questions cannot be definitely answered [dürfte aus "ethischen Prämissen" unaustragbar sein]. The ethical problem in most social-political issues is, however, of this type (Weber 1949: 15-16).

The existence of pervasive deep disagreements on social and political justice has also been demonstrated by recent research (Knoll 2019a; this article builds on research of Hampshire 1999, Herwig 1984, Knoll 2009, Waldron 1999. For a related voluminous study, see Besson 2005, cf. Warnke 1993). It shows that from the ancient world to the present day two irreconcilable basic conceptions of social and political justice - an egalitarian and a non-egalitarian one - can be traced in Western political thought. While champions of egalitarian justice negate the natural and social inequalities of persons and hold that it is just to establish arithmetic or numeric equality, non-egalitarians or proportionalists like Plato, Aristotle, Nietzsche or Mill conceive of a just distribution of goods as proportional to existing inequalities. For non-egalitarians or champions of proportional justice, it is just to allot equal shares only to equals, not to everyone.

In 19th century philosophy, Karl Marx argues that the distribution of social wealth should be based exclusively on individual needs and thus be independent from unequal labor contributions to society (Marx 2009, cf. Knoll 2019a: 33-39). Several contemporary political philosophers such as Michael Walzer and David Miller recognize the importance of the "needs principle" for just distributions of social benefits (Miller 2003: 203-229, Walzer 1983: 25-26, 64-94, cf. Rawls 1971, $\S 47: 305)$. However, from the perspective of the performance or merit principle, it is extremely unjust if persons who contribute more to society receive significantly less than those who contribute less. In contemporary political philosophy, a similar conflict on social justice is central to the disagreement between Rawls and Nozick. Rawls's basic moral conviction is that inequalities of birth and natural endowments are undeserved and call for social redress or compensation (Rawls 1971, § 17: 100108). Nozick deeply disagrees with the amount of taxation and redistribution of income Rawls's conception of justice requires (Nozick 1974: 168-69, 225, 228). Philosophical disagreements on social and political justice further substantiate the thesis that deep disagreements exist that prove to be resistant to rational solution. Such kinds of "reasonable disagreements" 6 are particularly significant because they are based on elaborate but opposing philosophical theories each of which are defended with carefully constructed arguments.

Deep moral disagreements are also a characteristic of ethics as a subdiscipline of philosophy. The three main ethical theories are virtue theory, consequentialism (traditionally called Utilitarianism), and deontological theories (Kant). Among these

\footnotetext{
6 "Resonable disagreement is disagreement that survives the best efforts of a group of reasoners to answer a particular question - that is, to find a unique answer that is required by reason" (McMahon 2009: 2). "People may be said to disagree reasonably about justice when, despite thinking and conversing in good faith and doing their best to apply the general capacities of reason pertaining to the domain of inquiry, they cannot converge on a view of justice on the same grounds, be it in a particular case or at a more abstract level" (Besson 2005: 1).
} 
three, a deontological and a consequentialist approach to ethics and morality are irreconcilably opposed to each other. A deontological ethics claims that certain actions are always right or wrong in certain situations, no matter what the consequences are. A consequentialist ethics, on the contrary, holds that the judgment about the moral rightness or wrongness of an action depends exclusively on the quality of its foreseeable consequences (for the term 'consequentialism', see Anscombe 1958). These two approaches to ethics do not allow for consensus or compromise. An ethicist has to choose whether actions or consequences are the appropriate domain of moral assessment.

\section{From theoretical disagreement to practical conflict: the virtues of acknowledging deep disagreements and of recognizing opposing positions as worthy of respect}

The preceding section has demonstrated the existence of myriad widespread deep disagreements on values, justice, morality, and ethics, which are resistant to rational solution. These disagreements pose a serious challenge to our interactions with the people we disagree with as private persons, as citizens, and as researchers, experts and philosophers. We must come to terms with them and inquire into the attitudes, behaviors, and actions we should take towards those with whom we disagree, but have to live with. It is tempting to assert that our own moral and ethical views are right and justified and the opposing views are wrong and illegitimate. In particular for a moral objectivist, ethical realist, and cognitivist, it might seem obvious that the moral relativist and skeptic is either incapable of perceiving the objective moral truths or unwilling to acknowledge them. ${ }^{7}$ It is equally tempting to assume that our personal values, in particular if we believe that we consciously and freely chose them out of the globally available pool, are superior to those of others. A related temptation consists in degrading epistemic peers we disagree with as ignorant, insincere, irrational, unintelligent, prejudiced, malicious, and the like. The more we become aware of the force of the arguments for the actual existence of deep disagreements, the less we are tempted to do so, and the more we are prepared to acknowledge reasonable disagreements as part of the human epistemic condition. The previous section laid out some of these arguments. However, more research on the reasons for the existence of deep disagreements and the capacities of human reason is desirable. ${ }^{8}$ Encouragingly, a new research area called "epistemology of

\footnotetext{
Andrew Mason distinguishes between two conceptions of political disagreement. He contrasts "the contestability conception" with the "imperfection conception". For the latter, which is "committed to a form of cognitivism", in political disagreements "at least one party to the dispute is mistaken" (Mason 1993: 2-3).

8 For research on the sources of reasonable and moral disagreement, see Besson (2005: 17-119), Gutmann and Thompson (1996: 18-26), and Knoll (2019a: 39-43). One reason for deep disagreements is what Rawls calls the "burdens of judgment" (Rawls 2005, II $\S 2: 54-58$ ). It would be desirable if future research on disagreements included a Nietzschean perspective, according to which human understanding is fundamentally related to drives, affects, and passions.
} 
disagreement" focuses "on determining the properly rational attitude to adopt in the case of acknowledged disputes between epistemic peers" (Machuca 2013b: 2). ${ }^{9}$

In the following sections, this article argues that in order to come to terms with deep disagreements we should develop an ethics of disagreement. Most fundamentally, such an ethics asks opposing parties in moral and intellectual conflicts to acknowledge that deep disagreements exist. This means that, without evidence or good reasons, conflicting parties should refrain from dismissing those they disagree with as inapt, irrational, ignorant, backward, prejudiced, untrustworthy, vicious, and the like (cf. Langerak 2014: vii). In many cases this is clearly an oversimplification of the matter. On closer inspection we have to admit that those with whom we disagree often are as informed, competent, intelligent, and good-willed as we are. Of course, there are cases in which we conflict with epistemic inferiors. In their fields of expertise, experts are commonly considered to be epistemic superiors when compared to non-experts, and students are usually acknowledged to be epistemic inferiors to their professors in the area they are taught. However, in such cases the disagreements are often not deep and can be resolved if the epistemic superior shares information, reasons, and arguments with her inferior. It could be argued that in disputes we should generally proceed with the presumption that our opponents argue in good faith and have the expertise they claim unless we have evidence that they do not.

Respecting the fact that deep disagreements on values, justice, and moral issues exist does not only mean that we should refrain from degrading our opponents. It also means that one should recognize an opposing position as worthy of respect even if one thinks that it is mistaken. There are several epistemic reasons for this. As already mentioned, value conflicts cannot be rationally decided. Weber's claim is convincing that it is, e.g., impossible to scientifically assess and compare the value of French and German culture (Weber 1946: 148). Similarly, we are not able to decide rationally which of two opposing reasonable theories of justice is the most appropriate, let alone the true one. Furthermore, no rational procedure exists that allows for a decision on whether to prefer a deontological or a consequentialist approach to ethics and morality.

Both as individuals and as members of the human species we should avoid "epistemic arrogance", which has been defined as "a complex social-psychological attitude that contrasts with what is sometimes called open-mindedness and with what others have called intellectual humility" (Lynch 2018: 133),

The attitude I'm calling epistemic arrogance can be roughly described as an unwillingness to regard your worldview (or some aspect of it) as capable

9 In the informative introduction to his volume on the skeptical implications of disagreement, Machuca explains that there are mainly two types of views adopted in the literature. According to "steadfast or uncompromising views", in "at least quite a number of cases it is perfectly rational or reasonable to retain one's belief in the face of a dispute with someone whom in general one regards as an epistemic equal" (Machuca 2013b: 5). Such views are opposed to "conciliationist" views that maintain "that, in the face of revealed peer disagreement, all the parties to the dispute are rationally required to significantly revise their beliefs" (Machuca 2013b: 3). For a textbook on disagreement and the epistemology of disagreement, see Frances (2014). For research literature on the epistemology of disagreement, see Christensen and Lackey (2013), Feldman and Warfield (2010), Matheson (2015), Weber (2019). 
of epistemic improvement from other people's knowledge or experience. People who are epistemically arrogant are know-it-alls. That's a motivating state - it motivates you to not only stop inquiring, but at its extremes, to brook no objection to your views. To be epistemically arrogant is to be dogmatic in the common sense of the term (Lynch 2018: 134).

As individuals we should be open both to regarding parts of our assumed knowledge as unjustified and to changing our views on a wide range of topics. The opposite of 'epistemic arrogance' could be called 'epistemic modesty' or 'epistemic humility'. As members of the human species such an attitude is primarily suggested because of the shift of our views of the world and our epistemic situation since Copernicus, the Enlightenment, Darwin, Nietzsche, and Freud. Since the biological theory of descent and the severe critique of religion over the past centuries, it has become difficult to conceive of the human being as God's creature and similitude. For most philosophers, God ceased to be the guarantor of the possibility of true knowledge or the agreement of our concepts or thoughts to the world..$^{10}$ Similarly, human reason is no longer considered to be a divine element in the human being as Plato and Aristotle taught (Plato, Republic VI 490b, VII 518e, X 611e, Aristotle, The Nicomachean Ethics X 7 1177b27 ff., Aristotle, Metaphysics XII $91074 \mathrm{~b} 15$ ff.). Rather, there are good reasons to regard the human animal with Herder, Nietzsche, and Arnold Gehlen as a "deficient being" (Mängelwesen) for it has e.g. no horns or claws (Gehlen 1988). To compensate for its deficiencies, the human being is endowed with reason (cf. Protagoras's myth of the origin of man, civilization, and the polis in Plato, Protagoras 321c-d). From an evolutionary perspective, rational cognition has primarily developed as a practical instrument for survival and self-preservation (cf. Nietzsche 1999: 142). To be sure, despite its likely origin, scientific progress demonstrates that reason is able to achieve an impressive amount of technically useful interpretations of the world. Nevertheless, a critical awareness of its place in the cosmos suggests epistemic humility to the human animal. Epistemic modesty recommends to rather ask questions than to make claims. As human rational capacities are limited and as humans are fallible beings, in moral and intellectual conflicts opposing parties should not be overconfident that their views are the only right or even the true ones. Therefore, they should recognize opposing views as worthy of respect and try to engage with them. Epistemic modesty is a central motivation for seeking dialogue and for hearing the reasons and arguments our opponents adduce for their positions. Awareness of the existence of deep disagreements, however, should limit our hopes to reach consensus with those with whom we engage in moral argument.

An ethics of disagreement asks the opposing parties in moral and intellectual conflicts to refrain from degrading the persons they disagree with unless they can justify this with good arguments. The reason is not only that this often amounts to a

${ }^{10}$ Aristotle assumed the agreement of our concepts to the world. According to him, the 'things' (pragmata) of the world cause notions in our 'soul' (psychê) that are their 'alike images' (homoiomata) (De interpretatione 16a3-8). This understanding of the unity of thought and reality was still presupposed by Thomas Aquinas in the 13th century (Quaestiones Disputate De Veritate 1-13). 
condescending epistemic arrogance and a lack of awareness of both the existence of deep disagreements and the human epistemic condition. Perceiving one's opponent as irrational, inept, immoral, evil or of lower human worth also often has dangerous practical consequences (cf. Waldron 1999: 111). Dismissing disagreement "as merely a symptom of the stupidity or wickedness of one's opponent" is particularly dangerous in a democracy because "proper practices of argument are crucial for the health of a democratic society" (Aikin and Talisse 2014: XV).

There is an obvious correlation between theoretical disagreement and practical conflict. Take the theoretical dispute between a localist, a nationalist, and a cosmopolitan on whether we all belong to a single community or which community is morally deserving of our primary political loyalty. In such a debate all three will be able to defend their views with reasons and arguments, but it is impossible to rationally decide which one of the three views and values is more desirable or worth choosing. However, if the localist and the nationalist want to put their views into practice, they have to face the fact that their values are defined and constructed in relation to a set of values each of them opposes. If the localist wants to act on her values, she might join a separatist movement, which aims at breaking away from her nation, e.g. Spain, a nation that she accuses of exploiting and suppressing her own region in an immoral and unjust way. If a proud nationalist wants to live up to his national identity, he should be aware that such a concept usually goes along with antagonisms and the devaluation of other nations who are not only perceived as competitors but often as enemies. History shows that both German and French nationalists were frequently convinced of the comparatively lower value of the other culture. Those holding such a conviction likely are inclined to seek conflict and - as was for a long time the case in the unfortunate history of both countries - even war against the neighbor. At the beginning of World War I, when nationalism reached a new peak, a vast number of citizens of different nations enthusiastically welcomed the outbreak of the war (cf. Zweig 1964). Today, Turkish nationalists mostly support the 2016, 2018, and 2019 prolonged incursions of Turkish military into Syria. In Book V of the Politics, in which Aristotle examines civil wars, he argues that many of these wars started in the past because a group of citizens was either fully excluded from political power or at least found its precise distribution to be unjust. Until today, justice conflicts often are the cause of civil wars. The civil war in Syria, which started in 2011 during the so-called 'Arab Spring', began with peaceful protests against the injustice of the authoritarian regime of Baschar al-Assad, who upon coming to power disappointed citizens' hopes for reform. Against this, the opposition initially aimed merely at democratization.

The correlation between theoretical disagreement and practical conflict exists not only on the level of disputes about values and conceptions of justice. Theoretical disagreements on moral issues such as abortion also have a crucial practical and political dimension. Legislators have to make laws about abortion and not all citizens, say Catholics in the US, agree with these laws. The value conflict between the life of a fetus and the liberty of a woman can easily turn into a conflict between persons. The theoretical disagreements among such persons can in extreme cases lead to 
violent actions by anti-abortion radicals. If an antiabortion advocate is convinced of the high value of fetal life and perceives abortion-performing doctors as murderers, he might become an anti-abortion radical who tries to kill such doctors. In this case, the abortion-performing doctor is perceived not only as someone who disagrees with him in the abortion debate by thinking that a fetus is not yet a person and therefore still does not enjoy a full right to life. Rather, the abortion-performing doctor is seen as a highly immoral, even evil, person.

An ethics of disagreement is best conceived of as a form of virtue ethics. Virtues are usually defined as "trained behavioral dispositions that result in habitual acts of moral goodness" (Pojman and Fieser 2012: 146-147). In the Nicomachean Ethics, Aristotle distinguishes between ethical virtues (aretai êthikai), virtues of character (Books II-V), and intellectual virtues (aretai dianoêtikai), virtues of the mind (Book VI). Correspondingly, he holds a 'virtue' (aretê) to be either an 'excellence' or 'best-state' of character or of the mind. The virtues of character such as justice and moderation are developed through habituation by moral education and good laws starting from childhood; the virtues of the mind such as prudence and wisdom are cultivated through learning and studying, which requires experience and time (Nicomachean Ethics, Book II 1, cf. Fermani 2019: 161-167). An ethics of disagreement understands the desirable cognitive attitudes of acknowledging deep disagreements on values, justice, morality, and ethics, and of recognizing an opposing position as worthy of respect, as cardinal virtues. Although they are mainly intellectual virtues, they have immediate ethical and practical implications. If I do not recognize an opposing position as worthy of respect, I might be drawn to exclude, suppress, coerce or even fight the person who holds it. Such a lack of recognition also removes the motivation for seeking dialogue and mutual understanding with the persons we disagree with. However, insight into the human epistemic condition and thus epistemic humility should motivate us to listen to them and to examine the reasons and arguments their positions are based on. Seeking dialogue and mutual understanding with those we disagree with is another cardinal virtue of an ethics of disagreement.

\section{The virtue of seeking dialogue and mutual understanding with the persons we disagree with}

Acknowledging deep disagreements on values, justice, and moral issues and recognizing opposing positions as worthy of respect should be strong motivations for engaging with them and for trying to understand them. This is particularly relevant in the field of politics. The virtue of seeking dialogue and mutual understanding with the persons we disagree with is both a moral and a political virtue. Political systems and legislators have to deal with the moral disagreements and value conflicts of their citizens and make decisions about them. They have to aim at methods and procedures that lead to solutions for moral disagreements and value conflicts that citizens can accept. One of the key conflicts pertaining to the political sphere is the clash 
between equality and liberty. In political philosophy, this conflict is represented by the opposition and disagreement between the theories of Rawls and Nozick (Rawls 1971, 2001, 2005, Nozick 1974).

An ethics of moral disagreements favors a democratic political system because, in principle, such a system treats all citizens as equals and should therefore respect their dissenting views equally if they are "reasonable". Unreasonable views such as the views of extreme racists or radical fundamentalists cannot be tolerated (cf. section 5). A democratic political system should not repress reasonable dissenting views but allow them to compete in the public sphere. An ethics of moral disagreement in politics promotes dialogue and mutual understanding between citizens by putting emphasis on freedom of the press, free speech, public debates, and public reason (for a vigorous defense of the liberty of thought and discussion, see chap. II of Mill 1991). The modern idea of public reason goes back to Kant and is in particular advocated by Kantians such as Habermas and Rawls (Horster 1999: 18-20, Rawls 2005: 212-54). Rawls refers to "Kant's distinction between public and private reason in 'What is Enlightenment' (1984)" and to "other relevant discussions in Kant's works, for example, Critique of Pure Reason, B767-97" (Rawls 2005: 213, fn. 2). According to Rawls, public reason is the reason of equal citizens or "the public"; it is "characteristic of a democratic people" aiming at the public good and political justice (Rawls 2005: 213). The ideal of public reason holds for citizens when they discuss "in the public forum" and thus applies to "members of political parties", "candidates in their campaigns", legislators speaking in parliament, "to the judiciary and above all to the supreme court" whose "justices have to explain and justify their decisions" (Rawls 2005: 215-16).

The ideal of public reason is closely linked to the ideal of deliberative democracy which is "a conception of democracy that secures a central place for moral discussion in political life" (Gutmann and Thompson 1996: 1). An ethics of moral disagreement in politics supports deliberative democracy and its emphasis on moral argument. The "theoretical principles" of moral argument have been successfully examined by Amy Gutmann and Dennis Thompson who explain deliberative democracy thus: "The core idea is simple: when citizens or their representatives disagree morally, they should continue to reason together to reach mutually acceptable decisions" (Gutmann and Thompson 1996: 1; for a volume with critical essays of leading political theorists and ethicists on Gutmann and Thompson's book see Macedo 1999). The crucial question is, however, what may we realistically expect as outcome of discussions and moral arguments in the public sphere? In several of his writings, Jürgen Habermas holds that unimpeded discourses and arguments based on communicative reason are generally able to solve disagreements and lead to consensus in moral issues (Habermas 1991). Similarly, Rawls hopes for a rational agreement or an "overlapping consensus" on a political conception of justice. Like discourse, consensus is a central value of contemporary proponents of deliberative democracy. Most of them believe that deliberations ideally aim at rational agreement (cf. Waldron 1999: 91-93). In response to this, Jeremy Waldron states "that in the real world, even after deliberation, people will continue to disagree in good faith about the common good, and about the issues of policy, principle, justice, and right which we 
expect a legislature to deliberate upon" (Waldron 1999: 93). For Stuart Hampshire, as for Waldron, modern societies are "morally mixed" as they contain conflicting or "rival conceptions of justice" (Hampshire 1999: 38). Both Hampshire and Waldron suggest refraining from the unrealistic aim to overcome justice conflicts by a form of consensus (Waldron 1999: 1-2). Rather, Hampshire holds that we should focus on a fair "adjudication of conflicts" following the "adversary principle of hearing both sides" aiming at compromise (Hampshire 1999: 22-23, 45).

As we have to accept the existence of widespread and deep disagreements on values, justice, ethics, and moral issues, we should overcome the unrealistic ideal and goal of a consensus on such matters achieved by citizens and practical philosophers. Nevertheless, this does not mean that moral discussions and arguments are futile or that the ideals of public reason and deliberative democracy cannot be realized at least partially. As professional moral or political philosophers we study opposing moral and political views quite thoroughly. After we understand them, we may disagree and argue against them, but we may also approve, defend, and further develop them. As citizens it is more difficult to rationally engage with opposing moral and political views and to get a chance at coming around to another's point of view. First of all, most of us are inclined to keep opposing points of view at a distance. We socialize with like-minded people, read "our" newspaper or blog, and usually have little time to research unfamiliar views. Furthermore, we tend to degrade our opponents, consciously or not, as extreme leftists or extreme rightists, as radical, bone-headed, ignorant, insincere, sinister, wicked, and so on. If we dismiss our opponents in such ways, we preclude ourselves from engaging with their views. If we want to have a chance to modify or change our moral and political views, we have to overcome such common behaviors, habits, and biases. Instead, we have to listen to the reasons and arguments our opponents offer for their positions.

A realistic understanding of politics, which acknowledges both deep moral disagreements and serious value conflicts in the political sphere, does not hope for agreement or consensus. While a consensus on values, justice and moral issues seems often impossible, an agreement on "procedural justice" is realistic (cf. Hampshire 1999: 29). To be sure, an ethics of moral disagreement in politics supports the ideals of public reason and deliberative democracy and defends the virtue of seeking dialogue and mutual understanding. Nevertheless, despite deliberations and extensive moral discussions in public forums, it is impossible to resolve many moral or political disagreements. Therefore, an ethics of disagreement will promote methods and procedures capable of resolving such disagreements peacefully. Among those are negotiations, bargaining, and compromises. ${ }^{11} \mathrm{~A}$ central procedure for resolving

${ }^{11}$ For the relation of public reason and compromise, see Lim (2019). Going back to Rousseau's political philosophy, Martin Ebeling claims to "introduce a new conception of democracy" which he calls "conciliatory democracy". According to this conception, citizens should deal with their political disagreements by applying the "ideal of epistemic conciliation", i.e. by "finding a middle ground" between "conflicting judgments". Ebeling asserts that this ideal "replaces the ideals of consensus and of a compromise of interests at the center of much of democratic theory today" (Ebeling 2017: VII). However, later in the book he admits that "there exists considerable overlap" between "the ideas of epistemic conciliation and of fair compromise" (Ebeling 2017: 188, cf. 170, 184-188). 
conflicts in a democracy peacefully and fairly is majority rule, which realizes both political equality among citizens and popular rule. ${ }^{12}$ An ethics of disagreement has a crucial normative commitment and interest in keeping moral and political disagreements from escalating and turning into violent conflicts or even civil wars. As one way to prevent this from happening, an ethics of disagreement thus promotes toleration as a moral and political virtue.

\section{Toleration as a moral and political virtue}

Toleration generally starts off with the judgment that some behaviors, beliefs or values are objectionable for some reasons. Without such a negative moral, epistemic or aesthetic judgment - e.g. if we recognize such behaviors, beliefs or values or if we are indifferent toward them - there would be no need for tolerance (in this section, 'toleration' and 'tolerance' are used interchangeably). Toleration also presupposes that the objection to a behavior, belief or value is not so radical that it cannot be overridden or trumped by reasons for accepting it anyway. This combination of disapproval and acceptance is usually called the 'paradox of toleration' (Forst 2013: 21-22, Horton 1976: 28, King 1998: 29-33, Mendus 1989: 18-19, Tan 2019: 385). Central questions about toleration concern (a) the reasons to object to beliefs, forms of life, values and moral views, (b) the reasons to accept them nonetheless, and (c) the relation between these reasons.

There are wider and narrower conceptions of toleration. According to narrower ones, e.g., we should speak of toleration only when the "restraint in the response to another's belief or action is based on some specifically moral grounds" (Heyd 1996: 4, cf. 14) or "in situations that make it very difficult" to "tolerate other people and their way of life" (Williams 1996: 18). In contrast, this section is based on a rather wide conception of toleration. We should distinguish between toleration as a legal and political practice and as an attitude of an individual or group. If persons or groups disapprove behaviors, beliefs or values and have the power to interfere with them, they will abstain from doing so if they tolerate them. Similarly, tolerant persons hold that the state should not use its power to suppress or prevent an array of beliefs, behaviors or values they object to.

Acknowledging deep disagreements on values, justice, and moral issues and recognizing opposing positions as worthy of respect has important consequences for the debate on toleration. If we have good reasons to acknowledge deep disagreements and to respect opposing positions, we also have good reasons to tolerate the values and moral views we disagree with. If we accept that consensus or agreement is an ideal hardly to be realized, we should be more inclined to tolerate values and moral views we disapprove of. The argument for toleration from deep disagreements rests on an epistemological justification of toleration; itself based on 'moderate skepticism' or

${ }^{12}$ For the distinction between two conceptions of democracy, procedural and constitutional, and their relation to moral disagreement, see Gutmann and Thompson (1996: 26-39). 
'moderate relativism', or both. ${ }^{13}$ It is not the only possible justification of toleration and should be combined with others (for different approaches, see Forst 2000: 1619). Significant other justifications of toleration are respect for the value of individual or personal autonomy and respect for persons as fellow citizens (cf. Raz 1987, Tan 2019: 397, Williams 1996: 22, 24-26; on equal respect see also Walzer 1983: 276280). According to an additional important justification of toleration, this attitude or virtue promotes peaceful coexistence of those who disagree with each other, but have to live together. ${ }^{14}$

The argument for toleration from deep disagreements rests on insights into the human epistemic condition; it relies particularly on the arguments for the existence of deep disagreements on values, justice, ethics and moral issues. If moral truth or moral knowledge does not exist, then there is no absolute standard to assess opposing values, moral convictions and conceptions of justice. Therefore, none of them can claim precedence and all reasonable ones have a claim to be respected and tolerated. If we abstain from degrading our epistemic opponent and admit that she defends merely a different yet reasonable position, we have a reason for respecting and tolerating this position. In this context the term 'reasonable' serves to designate the limits of respect and toleration. Unreasonable values, moral convictions, conceptions of justice, and behaviors cross those limits by being harmful, violent, destructive or somehow intolerable to others. The limits of toleration are determined by the point when the reasons for rejecting a position or behavior are stronger that the reasons for accepting it.

As Locke and Mill are among the early defenders and theoreticians of tolerance, toleration is commonly understood as a liberal virtue (for the history of toleration see Forst 2000: 10-16, Forst 2013: 36-446, Heyd 2008: 173-176). Indeed, toleration is usually recognized as being both a moral and a political virtue (Forst 2000: 8, Horton 1976: 28-29, Mendus 1989: 18-19, Tan 2019: 395). Nevertheless, David Heyd claims that toleration is neither a political concept nor a political virtue; it is "not a virtue in the narrow sense" but "an attitude of individuals (or groups) towards each other" (Heyd 2008: 172, 179). Heyd argues that the main task of modern liberal democracy, or the liberal state, is to "respect and protect the rights of both

${ }^{13}$ For 'moderate skepticism' and 'moderate relativism', see the end of section 1. For relativist arguments for tolerance and criticisms of such arguments, see Wong (1984: 177-197). Wong engages with the criticisms of Harrison (1979) and Williams (1972). For later criticism of Wong's relativist argument, see Graham (1996) and McKinnon (2006: 39-43). In three chapters, McKinnon critically discusses (a) a variety of skeptical arguments for toleration, (b) the pluralist justifications of toleration offered by Isaiah Berlin and Joseph Raz supposedly relying on the incommensurability of values, (c) a justification of toleration drawing on Rawls's idea that persons are reasonable which rejects intolerance as unreasonable (McKinnon 2006: 35-80). For the relation of disagreements to relativism and skepticism, see Ribeiro (2011: 9-11).

${ }^{14}$ For a rather divided country such as modern Turkey, which is still struggling to find a common ground, toleration is also recommended for pragmatic reasons. If the political representatives of the part of society that considers itself secular tolerate e.g. women wearing headscarves in public positions, and if the political representatives of the part that regards itself religious tolerate e.g. people drinking alcohol in public, all have an advantage no matter which group is temporarily in power and governs the country. 
individuals and groups" (Heyd 2008: 177). Combined with the rule of law, equality, and justice, this task does not "leave room for state tolerance"; indeed it allegedly tends "to make toleration politically redundant" (Heyd 2008: 175, 177-78). Heyd illustrates this point by claiming that the "legal status of minorities" or "freedom of expression" is "a matter of rights rather than of toleration by the state" (Heyd 2008: 178). Heyd's argument neglects the fact that many rights, and the liberties they grant, are best interpreted as legal embodiments and political expressions of toleration. Similarly, Bernard Williams argues that the modern impartial, pluralist, liberal state "can be seen as enacting toleration" (Williams 1996: 22, 24). Freedom of speech and the rights that protect minorities and their (religious) beliefs express toleration toward offensive utterances and the beliefs of these minorities. The freedom of the press means that governments are legally bound to tolerate views and criticisms they repudiate. Toleration is both a moral virtue of individual persons or groups and a political virtue embodied in modern democratic political systems.

\section{Conclusion}

The virtue of tolerating opposing beliefs, behaviors, forms of life, values, and moral views is a minimum that we can expect from individuals, groups, and political systems in a world of deep disagreements on values, justice, and moral issues. The virtue of seeking dialogue and mutual understanding with the persons we disagree with is more demanding than just toleration. However, insights into the human epistemic condition and the correlation between theoretical disagreement and practical conflict should motivate us to practice this virtue. This article could only outline an ethics of disagreement. Further research on the topic and a further elaboration of the proposed ideas are desirable. So far, theoretical disagreements in various fields of philosophy have been studied and discussed extensively. It is now time to focus on how to practically and ethically deal with such disagreements, particularly with disagreements on values, justice, and moral issues.

A central claim of this article is that an ethics of disagreement is best conceived of as a form of virtue ethics. Nevertheless, this approach is open to amendment by elements from a consequentialist ethics. ${ }^{15}$ All the virtues this paper has proposed for an ethics of disagreement can also be justified by their good or desirable consequences. If we acknowledge deep disagreements, recognize opposing positions as worthy of respect, seek dialogue and mutual understanding, tolerate opposing behaviors, beliefs or values, then we will in most cases also reduce practical conflicts and promote a peaceful coexistence among those who disagree, but have to live together. In doing so, of course, we also promote an increase in pleasure and a reduction of pain and suffering among people, citizens, and cultures in a world of deep disagreements on values, justice, and moral issues.

${ }^{15}$ John Stuart Mill makes quite clear that his version of consequentialism is compatible with virtue ethics, which focuses on a good "habitual disposition" or a "good character" and on "habitual motives of action" (Mill 1998: 64-67). The utilitarian doctrine "maintains not only that virtue is to be desired, but that it is to be desired disinterestedly, for itself" (Mill 1998: 82, cf. 84, 86). The longest chapter of Mill's Utilitarianism discusses the close connection between "Utility", or "the Greatest Happiness Principle", and the virtue of justice. 
Address:

Manuel Knoll

Mainzer Str. 7

80804 München, Germany

E-mail: Manuel.Knoll@1rz.uni-muenchen.de,

manuelknoll@hotmail.com

\section{References}

Aikin, Scott F. and Robert B. Talisse (2014) Why we argue (and how we should): a guide to political disagreement. New York and London: Routledge.

Anscombe, G.E.M. (1958) "Modern moral philosophy”. Philosophy 33, 124, 1-19.

Berlin, Isaiah (1997) "The pursuit of the ideal". In Isaiah Berlin. The proper study of mankind: an anthology of essays, 1-16. Ed. by Henry Hardy and Roger Hausheer. London: Chatto \& Windus.

Berlin, Isaiah (2013) “The originality of Machiavelli”. In Isaiah Berlin. Against the current: essays in the history of ideas, 33-100. 2nd ed. Ed. by Henry Hardy. Princeton and Oxford: Princeton University Press.

Besson, Samantha (2005) The morality of conflict: reasonable disagreement and the law. Oxford and Portland, Oregon: Hart Publishing.

Birnbacher, Dieter (2003) Analytische Einführung in die Ethik. Berlin and New York: De Gruyter.

Bruun, Hans Henrik (2007) Science, values and politics in Max Weber's methodology. New expanded ed. (Rethinking Classical Sociology). Aldershot: Ashgate.

Christensen, David and Jennifer Lackey, eds. (2013) The epistemology of disagreement: new essays. Oxford: Oxford University Press.

Ebeling, Martin (2017) Conciliatory democracy: from deliberation toward a new politics of disagreement. London: Palgrave Macmillan.

Feldman, Richard (2005) "Deep disagreement, rational resolutions, and critical thinking". Informal Logic 25, 1, 13-23.

Feldman, Richard and Ted A. Warfield, eds. (2010) Disagreement. Oxford: Oxford University Press.

Fermani, Arianna (2019) Vita felice umana: in dialogo con Platone e Aristotele. Macerata: EUM.

Fogelin, Robert J. (2005) "The logic of deep disagreements". Informal Logic 25, 1, 3-11.

Forst, Rainer (2000) "Einleitung". In Rainer Forst, ed. Toleranz. Philosophische Grundlagen und gesellschaftliche Praxis einer umstrittenen Tugend, 7-25. Frankfurt am Main: Campus.

Forst, Rainer (2013) Toleration in conflict: past and present. Trans. C. Cronin. (Ideas in Context.) Cambridge: Cambridge University Press.

Frances, Bryan (2014) Disagreement. Polity Press: Cambridge.

Gehlen, Arnold (1988) Man: his nature and place in the world. New York: Columbia University Press.

Giorgini, Giovanni (2019) "Does democracy necessarily rest on relativism? The origins of the debate in Ancient Greece". In Christoph Riedweg, ed. Philosophie für die Polis. Akten des 5. Kongresses der Gesellschaft für antike Philosophie 2016, 95-122. Berlin and Boston: De Gruyter.

Gowans, Christopher W. (2000) "Introduction: debates about moral disagreements". In Christopher W. Gowans. ed. Moral disagreements: classic and contemporary readings, 1-43. London and New York: Routledge.

Graham, Gordon (1996) “Tolerance, pluralisms, and relativism”. In David Heyd, ed. Toleration: an elusive virtue, 44-59. Princeton: Princeton University Press. 
Gutmann, Amy and Dennis Thompson (1996) Democracy and disagreement. Cambridge, Ma. and London: The Belknap Press of Harvard University Press.

Habermas, Jürgen (1991) Erläuterungen zur Diskursethik. Frankfurt am Main: Suhrkamp.

Hampshire, Stuart (1999) Justice is conflict. London: Duckworth.

Harrison, Geoffrey (1979) "Relativism and toleration". In Peter Laslett and James Fishkin, eds. Philosophy, politics, society: fifth series, 273-290. Oxford: Basil Blackwell.

Herwig, Dagmar (1984) Gleichbehandlung und Egalisierung als konkurrierende Modelle von Gerechtigkeit. Eine systematische Analyse. München: Fink.

Heyd, David (1996) “Introduction”. In David Heyd, ed. Toleration: an elusive virtue, 1-17. Princeton: Princeton University Press.

Heyd, David (2008) “Is toleration a political virtue?". In Melissa S. Williams and Jeremy Waldron, eds. Toleration and its limits, 171-194, New York and London: New York University Press.

Horster, Detlef (1999) Jürgen Habermas zur Einführung. Hamburg: Junius.

Horton, John (1976) “Toleration as a virtue”. In David Heyd, ed. Toleration: an elusive virtue, 28-43. Princeton: Princeton University Press.

King, Preston (1998) Toleration. New ed. London and Portland, OR: Frank Cass.

Knoll, Manuel (2009) Aristokratische oder demokratische Gerechtigkeit? Die politische Philosophie des Aristoteles und Martha Nussbaums egalitaristische Rezeption. München and Paderborn: Fink.

Knoll, Manuel (2019a) "Deep disagreements on social and political justice: their meta-ethical relevance and the need for a new research perspective". In Manuel Knoll, Stephen Snyder, and Nurdane Şimşek, eds. New perspectives on distributive justice: deep disagreements, pluralism, and the problem of consensus, 23-51. Berlin and Boston: De Gruyter.

Knoll, Manuel (2019b) "Max Weber on politics, reason, and the clash of values and approaches to ethics". Dîvân. Journal of Interdisciplinary Studies 24, 47, 111-140.

Ladd, John, ed. (1985) Ethical relativism. Lanham, New York, and London: University Press of America.

Langerak, Edward (2014) Civil disagreement: personal integrity in a pluralist society. Washington, DC: Georgetown University Press.

Lim, Chong-Ming (2019) "Public reason, compromise within consensus, and legitimacy". In Manuel Knoll, Stephen Snyder, and Nurdane Şimşek, eds. New perspectives on distributive justice: deep disagreements, pluralism, and the problem of consensus, 225-241. Berlin and Boston: De Gruyter.

Lynch, Michael P. (2010) "Epistemic circularity and epistemic incommensurability". In Adrian Haddock, Alan Millar, and Duncan Pritchard, eds. Social epistemology, 262-277. Oxford: Oxford University Press.

Lynch, Michael P. (2018) "Epistemic arrogance and the value of political dissent". In Casey Rebecca Johnson, ed. Voicing dissent: the ethics and epistemology of making disagreement public, 129 139. New York and London: Routledge.

Macedo, Stephen, ed. (1999) Deliberative politics: essays on democracy and disagreement. New York and Oxford: Oxford University Press.

Machuca, Diego E., ed. (2013a) Disagreement and skepticism. New York and London: Routledge.

Machuca, Diego E. (2013b) "Editor's introduction". In Diego E. Machuca, ed. Disagreement and skepticism. New York and London: Routledge. 
MacIntyre, Alasdair (1988) Whose justice? Which rationality? Notre Dame: University of Notre Dame Press.

Mackie, John L. (1977) Ethics: inventing right and wrong. London: Penguin.

Marx, Karl (2009) Critique of the Gotha Programme. Dodo Press.

Mason, Andrew (1993) Explaining political disagreement. Cambridge: Cambridge University Press.

Matheson, Jonathan (2015) The epistemic significance of disagreement. London: Palgrave Macmillan.

McKinnon, Catriona (2006) Toleration: a critical introduction. (Routledge Contemporary Political Philosophy). London and New York: Routledge.

McMahon, Christopher (2009) Reasonable disagreement: a theory of political morality. Cambridge: Cambridge University Press.

Mendus, Susan (1989) Toleration and the limits of liberalism. London: Macmillan.

Mill, John Stewart (1991) “On liberty”. In his On liberty and other essays. Ed. by John Gray. Oxford: Oxford University Press.

Mill, John Stewart (1998) Utilitarianism. Ed. by Roger Crisp. Oxford: Oxford University Press.

Miller, Alexander (2013) Contemporary metaethics: an introduction. 2nd ed. Cambridge: Polity Press.

Miller, David (2003) Principles of social justice. Cambridge, MA.: Harvard University Press.

Nietzsche, Friedrich (1997) On the genealogy of morality. Ed. by Keith Ansell-Pearson, trans. by Carol Diethe. Cambridge: Cambridge University Press.

Nietzsche, Friedrich (1999) "On truth and lying in a non-moral sense". In his The birth of tragedy and other writing. Ed. by Raimond Geuss, trans. by Ronald Speirs. Cambridge: Cambridge University Press.

Nozick, Robert (1974) Anarchy, state, and utopia. Oxford: Basic Books.

Pojman, Louis P. and Fieser, James (2012) Ethics: discovering right and wrong. 7th ed. Belmont, CA: Wadsworth Cengage Learning.

Rawls, John (1971) A theory of justice. Cambridge: Belknap Press of Harvard University Press.

Rawls, John (1985) "Justice as fairness: political not metaphysical". Philosophy \& Public Affairs 14, $3,223-251$.

Rawls, John (2001) Justice as fairness: a restatement. Edited by Erin Kelly. Cambridge, Mass. and London: Belknap Press of Harvard University Press.

Rawls, John (2005) Political liberalism. Expanded ed. New York: Columbia University Press.

Raz, Joseph (1987) "Autonomy, toleration, and the harm principle". In Ruth Gavison, ed. Issues in contemporary legal philosophy: the influence of H.L.A. Hart, 313-333. Oxford: Oxford University Press.

Ribeiro, Brian (2011) "Philosophy and disagreement". Crítica. Revista Hispanoamericana de Filosofia $43,127,3-25$.

Rüther, Markus (2015) Metaethik zur Einführung. Hamburg: Junius.

Siegel, Harvey (2013) "Argumentation and the epistemology of disagreement". OSSA Conference Archive, Paper 157, 1-22.

Tan, Kok-Chor (2019) "The contours of tolaration: a relational account”. In Manuel Knoll, Stephen Snyder, and Nurdane Şimşek, eds. New perspectives on distributive justice: deep disagreements, pluralism, and the problem of consensus, 385-402. Berlin and Boston: De Gruyter.

Tersman, Folke (2006) Moral disagreement. Cambridge: Cambridge University Press.

Waldron, Jeremy (1999) Law and disagreement. Oxford: Oxford University Press.

Walzer, Michael (1983) Spheres of justice: a defense of pluralism and equality. New York: Basic Books. 
Warnke, Claudia (1993) Justice and interpretation. Cambridge, MA: The MIT Press.

Weber, Marc Andree (2019) Meinungsverschiedenheiten. Eine erkenntnistheoretische Analyse. Frankfurt am Main: Vittorio Klostermann.

Weber, Max (1946) "Science as vocation". In H. H. Gerth, and C. Wright Mills, trans. and ed. From Max Weber. essays in sociology, 129-156. Oxford: Oxford University Press.

Weber, Max (1949) “The meaning of 'ethical neutrality' in sociology and economics”. In Max Weber. The methodology of the social sciences, 1-47. Trans. and ed by Edward Shills and Henry Finch. Illinois: The Free Press of Glencoe.

Williams, Bernard (1972) Morality: an introduction to ethics. Cambridge: Cambridge University Press. Williams, Bernard (1996) “Toleration: an impossible virtue?". In David Heyd, ed. Toleration: an elusive virtue, 18-27. Princeton: Princeton University Press.

Wong, David B. (1984) Moral relativity. Berkley: University of California Press.

Zweig, Stefan (1964) The world of yesterday. Lincoln: University of Nebraska Press. 